\title{
The Origin of the Helical Twist Inversion in Single Component Cholesteric Liquid Crystals*
}

\author{
I. Dierking ${ }^{1}$, F. Gießelmann ${ }^{1}$, P. Zugenmaier ${ }^{1}$, K. Mohr ${ }^{2}$, H. Zaschke ${ }^{2}$, \\ and W. Kuczynski ${ }^{3}$ \\ 1 Institut für Physikalische Chemie der TU Clausthal, Arnold-Sommerfeld-Straße 4, \\ D-38678 Clausthal-Zellerfeld \\ 2 Institut für Organische Chemie, Martin-Luther-Universität Halle, Weinbergweg 16, \\ D-06120 Halle \\ 3 Institute of Molecular Physics, Polish Academy of Science, Smoluchowskiego 17/19 \\ PL-60-179 Poznan, Poland
}

\section{Z. Naturforsch. 49a, 1081 - 1086 (1994); received August 12, 1994}

\begin{abstract}
The cholesteric twist inversion by temperature variation of a single component thermotropic liquid crystalline system was experimentally investigated and is explained by the partial twisting power model, evaluating the temperature dependent pitch of five different configurations of a benzoic acid biphenyl ester with two chiral centers. The temperature dependence of the twisting power and the cholesteric pitch for several stereoisomeric compounds can in first approximation be predicted by the partial twisting powers of the individual chiral centers determined from the partially racemic configurations.
\end{abstract}

Key words: Liquid crystal, Chirality, Cholesteric mesophase, Twist inversion.

\section{Introduction}

Few single component thermotropic liquid crystalline compounds are known to exhibit a cholesteric twist inversion with temperature, that is a change in handedness of the supermolecular helical structure of a cholesteric phase with temperature variation, leading to a nematic director configuration at the inversion temperature. The first low molecular thermotropic compound of this kind was a cholesterylester reported by Stegemeyer et al. [1]. At the same time the first thermotropic polymer to exhibit a twist inversion was published [2]. Further reports followed mostly on compounds containing an epoxy-group [3-6]. The chiral elements of such compounds do not necessarily imply chiral centers such as asymmetrically substituted carbons since a twist inversion of a cholesteric phase was observed whose molecules exhibit a chiral center and a chiral axis [7]. Recently, the first discotic compound showing a temperature induced twist inversion was reported [8].

The phenomenon of a cholesteric twist inversion in binary mixtures is long known [9], and substantial experimental work has been carried out on mixtures

\footnotetext{
- Presented in part at the 15. International Liquid Crystal Conference, Budapest, Hungary, July 1994.

Reprint requests to I. Dierking.
}

of thermotropic cholesteric liquid crystals $[10,11]$, of mesogenic [12-20] and also non-mesogenic [21, 22] chiral dopants in an achiral nematic matrix (induced cholesteric phases) or lyotropic systems [23-26]. Also the theoretical interpretation of a cholesteric twist inversion is limited to binary systems at the present. The formation of a nematic phase can be explained on the basis of induced dipole-dipole interactions (MaierSaupe theory [27, 28]), and by introducing dipolarquadrupolar interactions the spontaneous twist of the cholesteric phase for chiral molecules can be explained (Goossens theory [29]). But this basic theory cannot explain a temperature induced twist inversion, neither for mixtures nor in single component systems. An extended theory was introduced for binary mixtures [30-32], qualitatively explaining the twist inversion in terms of six interaction parameters. These parameters are not available for single component systems. Recently, Osipov $[33,34]$ published a description of the temperature and solvent dependence of lyotropic cholesteric phases, that is also binary systems.

At the present, no experimentally verified description of the temperature induced cholesteric twist inversion exists for a single component system. Two basically different hypotheses have been proposed and are discussed. One $[3,4]$ relies on a temperature dependent equilibrium between different conformers of a molecule which is difficult to be verified experimen- 
tally, although first efforts have been made [35]. For an experimental verification of this model the average concentration of each conformer has to be determined as a function of temperature. The other explaination $[1,5,36]$ relies on the effective partial twisting powers for each individual chiral element in a molecule, including handedness and temperature dependence, which are added up to yield the macroscopically observable twisting power of the cholesteric structure. For an experimental verification of this hypothesis, molecules are required for which the configuration of each chiral element can chemically be changed independently and which exhibit a temperature induced twist inversion of a cholesteric phase. The synthesis, characterization and verification of the twist inversion of such a compound was reported recently [36]. Here, measurements will be presented which quantitatively support the additive partial twisting power model.

\section{Experimental}

A benzoic acid biphenyl ester of the general formula

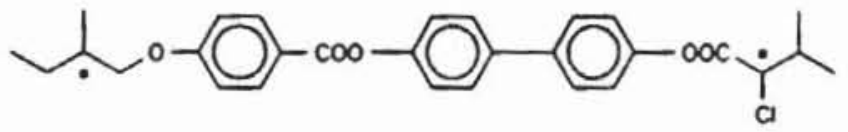

Center 1 temperature controller FP 5) regarding the mesomorphic behaviour of the differently configured compounds. The results are summarized in Table 1 . The samples were placed in $10 \mu \mathrm{m}$ commercially available LC cells (E.H.C. Ltd.), and the transition temperatures (in K) were determined by polarizing microscopy. Transition enthalpies (in $\mathrm{kJ} \mathrm{mol}^{-1}$ ) were determined from the DSC cooling traces with cooling rate $-5 \mathrm{~K} \mathrm{~min}^{-1}$. The transitions from the isotropic (I) to the blue phase (BP) and from the blue phase (BP) to the cholesteric phase $\left(\mathrm{N}^{*}\right)$ could not be resolved (n.r.) by DSC measurements, so that the specified transition enthalpy refers to the combined transition $\mathrm{I} \rightarrow \mathrm{BP}$ $\rightarrow N^{*}$. The phase denoted by $S_{x}^{*}$ is a tilted crystalline smectic phase, not yet certainly identified, presumably $\mathrm{S}_{\mathbf{G}}^{*}$.

The temperature dependence of the cholesteric pitch $\mathrm{P}$ was determined according to the color change method described in [5] using the same $10 \mu \mathrm{m}$ LC cells as for the previous investigations. These obtained data was checked by the Cano-Grandjean method $[37,38]$ and by wavelength measurements of the selective reflexion (cf. [36]). The handedness of the supermolecular cholesteric helices were obtained from the optical rotation by the method introduced in [39].

\section{Experimental Results and Discussion}

From basic symmetry considerations it is generally accepted for one-component systems that a change of the configuration at a chiral element of the molecule $(R \leftrightarrow S$ ) results in the change of the sign of the twisting power and of the handedness of the supermolecular

has been synthesized in five configurations: $(\mathrm{S}, \mathrm{S})$, $(\mathrm{S}, \mathrm{R}),\left(\mathrm{S}, \mathrm{RS}_{\mathrm{rac}}\right),\left(\mathrm{RS}_{\mathrm{rac}}, \mathrm{S}\right)$ and $\left(\mathrm{RS}_{\mathrm{rac}}, \mathrm{R}\right)$, and was characterized by calorimetric (Perkin Elmer DSC 7) and polarizing microscopic investigations (Olympus BH-2 equiped with a Mettler hot stage FP 52 and

Table 1. Mesomorphic behaviour, transition temperatures in $\mathrm{K}$ and transition enthalpics $\Delta H$ in $\mathrm{kJ} / \mathrm{mol}$ (numbers in brackets) for the five differently configured system of compound M96. The transition enthalpies for the I to BP and BP to $N^{*}$ transition could not be resolved (n. r.).

\begin{tabular}{|c|c|c|c|c|c|c|c|c|c|c|c|c|}
\hline $\begin{array}{l}\text { Center } \\
-1^{\prime \prime}\end{array}$ & $\begin{array}{l}\text { Center } \\
-2^{n}\end{array}$ & I & $\begin{array}{l}T / \mathrm{K} \\
(\Delta H / \\
\left.\mathrm{kJ} \mathrm{mol}^{-1}\right)\end{array}$ & BP & $\begin{array}{l}T / \mathrm{K} \\
(\Delta H / \\
\left.\mathrm{kJ} \mathrm{mol}^{-1}\right)\end{array}$ & $\mathrm{N}^{*}$ & $\begin{array}{l}T / \mathrm{K} \\
(\Delta H / \\
\left.\mathrm{kJ} \mathrm{mol}^{-1}\right)\end{array}$ & $\mathrm{S}_{\mathrm{C}}^{*}$ & $\begin{array}{l}T / \mathrm{K} \\
(\Delta H / \\
\mathrm{kJ} / \mathrm{mol}\end{array}$ & $S_{\dot{x}}^{*}$ & 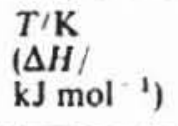 & Cryst. \\
\hline $\mathbf{S}$ & S & $\bullet$ & & +- & $\begin{array}{c}436.2 \\
(0.26)\end{array}$ & $\bullet$ & $\begin{array}{c}378.5 \\
(1.86)\end{array}$ & • & $\begin{array}{l}349.6 \\
(2.84)\end{array}$ & • & $\begin{array}{l}303 \\
(1.27)\end{array}$ & • \\
\hline $\mathbf{S}$ & R & $\bullet$ & $\begin{array}{l}432.7 \\
\text { (n.r.) }\end{array}$ & $\bullet$ & $\begin{array}{c}431.5 \\
(0.37)\end{array}$ & $\bullet$ & $\begin{array}{c}374.0 \\
(1.57)\end{array}$ & $\bullet$ & $\begin{array}{l}344.0 \\
(2.74)\end{array}$ & $\bullet$ & $\stackrel{303}{(1.08)}$ & $\bullet$ \\
\hline $\mathbf{S}$ & $\mathrm{RS}_{\mathrm{rac}}$ & $\bullet$ & & & $\begin{array}{c}436.3 \\
(0.44)\end{array}$ & $\bullet$ & $\begin{array}{c}371.3 \\
(1.38)\end{array}$ & • & $\begin{array}{c}341.2 \\
(2.46)\end{array}$ & • & $\begin{array}{l}298 \\
(1.20)\end{array}$ & $\bullet$ \\
\hline $\mathrm{RS}_{\mathrm{rac}}$ & S & - & $\begin{array}{l}425.1 \\
\text { (n.r.) }\end{array}$ & $\bullet$ & $\begin{array}{l}424.2 \\
(0.43)\end{array}$ & $\bullet$ & $\begin{array}{l}375.2 \\
(1.71)\end{array}$ & $\bullet$ & $\begin{array}{c}345.7 \\
(2.20)\end{array}$ & $\bullet$ & $\begin{array}{l}313 \\
(2.55)\end{array}$ & $\bullet$ \\
\hline $\mathrm{RS}_{\mathrm{tac}}$ & $\mathbf{R}$ & $\bullet$ & $\begin{array}{l}425.5 \\
\text { (n.r.) }\end{array}$ & $\bullet$ & $\begin{array}{c}424.3 \\
(0.45)\end{array}$ & $\bullet$ & $\begin{array}{c}375.5 \\
(1.82)\end{array}$ & • & $\begin{array}{c}345.5 \\
(2.52)\end{array}$ & $\bullet$ & $\begin{array}{l}309 \\
(2.33)\end{array}$ & $\bullet$ \\
\hline
\end{tabular}


helix. Furthermore, the twisting power can in first approximation be regarded as a linear function of temperature [40], excluding temperature intervals near phase transitions. As a measure for the helical twisting power we use in this paper the inverse pitch $p^{-1}$. The partial twisting power of a chiral element can thus be expressed as

$$
p_{j}^{-1}=a_{j} T+b_{j}
$$

with $j$ : chiral center index, $a_{j}$ and $b_{j}$ : coefficients, $T$ : temperature in $\mathrm{K}$.

The additive partial twisting power hypothesis states that the twisting powers $p_{j}^{-1}$ of individual chiral elements can be added up to yield a macroscopic power $P^{-1}$ leading to (2) if the chiral centers are regarded as independent, without any intramolecular coupling between them.

$$
P^{-1}=\sum_{j} p_{j}^{-1}=\sum_{j}\left(a_{j} T+b_{j}\right) .
$$

In first approximation this is an acceptable assumption as the chiral centers in the benzoic acid biphenyl ester molecule are about $20 \AA$ apart whereas the distance of nearest neighbors is about $4-5 \AA$. This means that intermolecular interactions should be much stronger than intramolecular interactions. At this level of approximation the influence of conformer equilibria on the cholesteric pitch are also neglected.

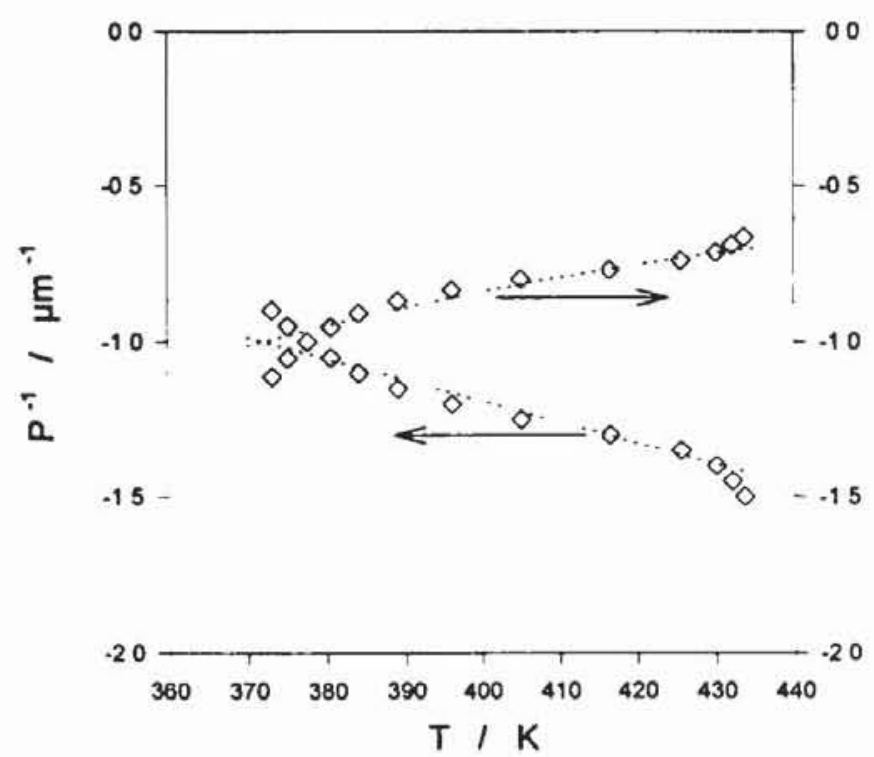

Fig. 1. Temperature dependence of the twisting power $P^{-1}$ and the cholesteric pitch $P$ of compound (S, RS rac)-M96. (o) experimental data, the dotted line corresponds to the calculated dependence from the linear best-fit for the twisting power. Negative values indicate a left handed helicoidal structure.
The experimental data for the twisting power $P^{-1}$ and the corresponding pitch $P$ as functions of temperature $T$ are presented for the five different stereoisomers (benzoic acid biphenyl ester, M96) in Figures $1-5$. The effective partial twisting power for the chiral center " 1 " in the S-configuration is obtained from the $\left(\mathrm{S}, \mathrm{RS}_{\mathrm{rac}}\right)$ configured M96 system, since only center

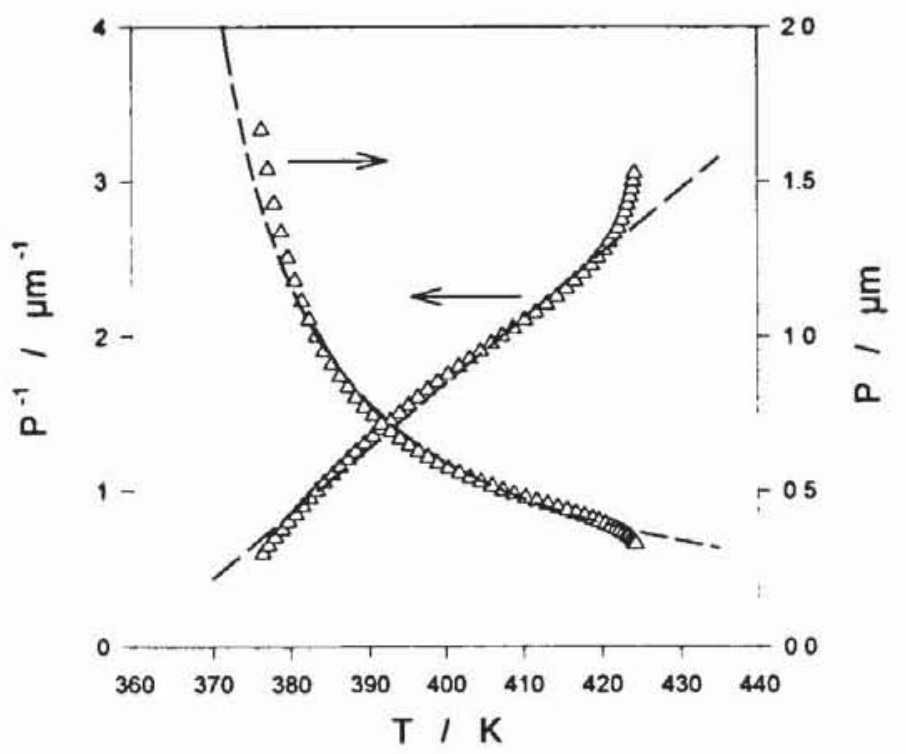

Fig. 2. Temperature dependence of the twisting power $P^{-1}$ and the cholesteric pitch $P$ of compound $\left(\mathrm{RS}_{\mathrm{rac}}, \mathrm{S}\right)-\mathrm{M} 96$. $(\Delta)$ experimental data, the dashed line corresponds to the calculated dependence from the linear best-fit for the twisting power. Positive values indicate a right handed helicoidal structure.

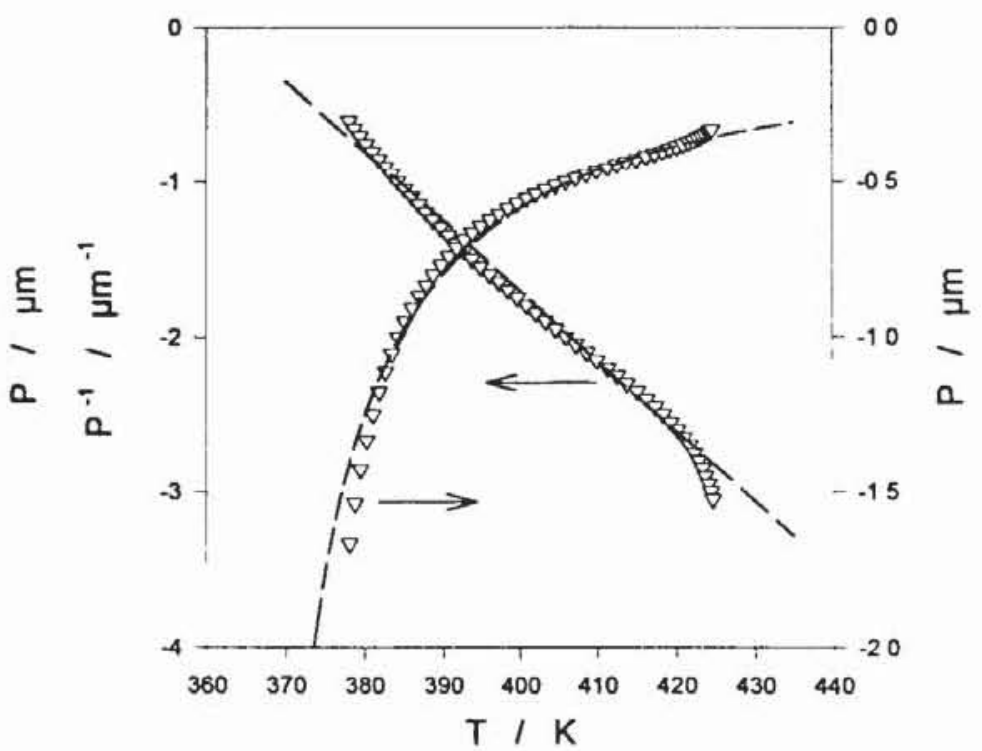

Fig. 3. Temperature dependence of the twisting power $P^{-1}$ and the cholesteric pitch $P$ of compound (RS $\left.\mathrm{R}_{\mathrm{rac}}, \mathrm{R}\right)-\mathrm{M} 96$. (v) experimental data, the dashed line corresponds to the calculated dependence from the linear best-fit for the twisting power. Negative values indicate a left handed helicoidal structure. 

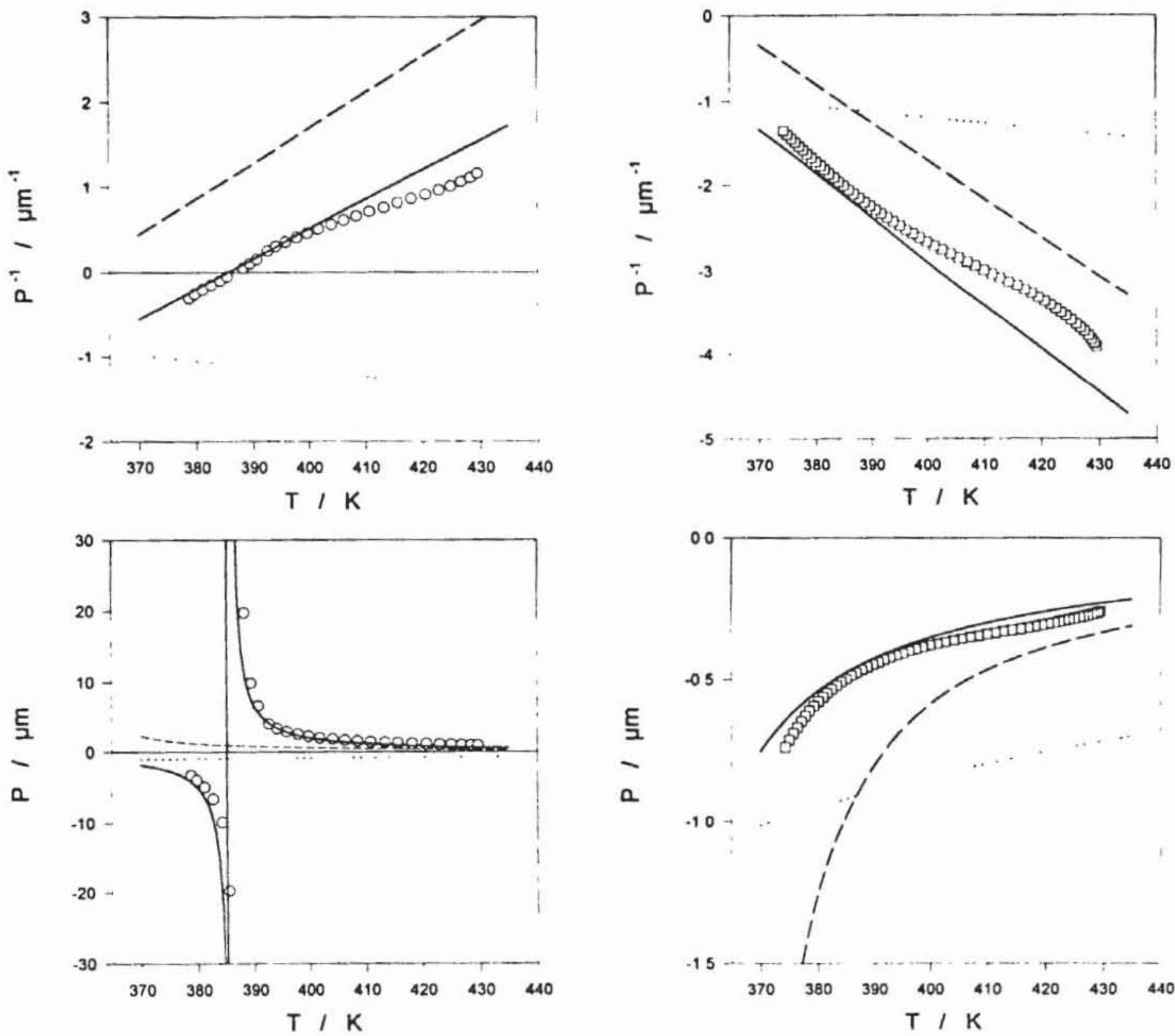

Fig. 4. (a) Temperature dependence of the twisting power $P^{-1}$ of compound (S, S)-M96 and (b) the corresponding cholesteric pitch $P$. (0) experimental data, the dotted line presents the calculated dependence on center ${ }^{\prime \prime}{ }^{\prime \prime}=S$, the dashed line on center " 2 " $=\mathrm{S}$ and the solid line presents the predicted temperature dependence for the (S, S)-configured system. Positive values indicate a right handed, negative values a left handed helicoidal structure.

"1" contributes to the macroscopic twisting power, and is represented with the best fit for a linear approximation (dotted line) in Fig. 1. The pitch of this system is also plotted as a function of temperature in Figure 1. The partial twisting power of center "2" of the $\mathrm{S}$ - and $\mathrm{R}$-configured systems may be derived from the $\left(\mathrm{RS}_{\mathrm{rac}}, \mathrm{S}\right)$ - and $\left(\mathrm{RS}_{\mathrm{rac}}, \mathrm{R}\right)-\mathrm{M} 96$ experimental data, of which the temperature dependence is depicted in

Fig. S. (a) Temperature dependence of the twisting power $P^{-1}$ of compound (S. R)-M96 and (b) the corresponding cholesteric pitch $P$. (a) experimental data, the dotted line indicates the calculated dependence on center ${ }^{\prime \prime} 1^{\prime \prime}=S$, the dashed line on center ${ }^{-2}=\mathrm{R}$ and the solid line presents the predicted temperature dependence for the ( $\mathrm{S}, \mathrm{R}$ )-configured system. Negative values indicate a left handed helicoidal structure.

Figs. 2 and 3 together with the pitch. The dashed line represents the best fit. The parameters which are associated with the partial twisting powers according to (1) are collected in Table 2 . As expected from the symmetry, the $a_{j}$ and $b_{j}$ parameters agree for the S- and $\mathrm{R}$-configured systems at center " 2 " in absolute values but have different signs. 
Table 2. Coeflicients $a_{j}$ and $b$, to describe the partial twisting powers of chiral centers " 1 " and " 2 ", calculated from twisting power measurements on the compounds (S, RS rac)-M96, $\left(\mathrm{RS}_{\text {rac }}, \mathrm{S}\right)-\mathrm{M} 96$ and $\left(\mathrm{RS}_{\text {rac }}, \mathrm{R}\right)-\mathrm{M} 96$. With these coefficients the temperature dependence of the twisting power and cholesteric pitch can be predicted for the diastereomeric configurations (S, S)-M96 and (S, R)-M96.

\begin{tabular}{lcrl}
\hline Configuration & $a_{j} / \mu \mathrm{m}^{-1} \mathrm{~K}^{-1}$ & $b_{j} / \mu \mathrm{m}^{-1}$ & Handedness \\
\hline$-1^{n}=\mathrm{S}$ & -0.0068 & 1.53 & left \\
$2^{n}=\mathrm{S}$ & 0.0418 & -15.03 & right \\
$-2^{-}=\mathrm{R}$ & -0.0453 & 16.42 & left \\
\hline
\end{tabular}

The partial twisting power model predicts the twisting powers of the two diastereomers, (S, S)-M96 and (S, R)-M96, by (2). The experimental and predicted data - dotted line for center " 1 ", dashed line for center " 2 " and full line according to (2) - are plotted in Figs. 4 and 5 . It should be noted that the range of values for the pitch is quite different for the two pure configurations, and that the inversion temperature, at which zero twisting power occurs, is well predicted (Fig. $4(\mathrm{a}))$. Considering the simplicity of the model, the

[1] H. Stegemeyer, K. Siemensmeyer, W. Scurow, and L. Appel, Z. Naturforsch. 44 a, 1127 (1989).

[2] T. Yamagıshi, T. Fukuda, T. Miyamoto, and J. Watanabe, Cellulose, Structural and Functional Aspects (J. F. Kennedy, G. O. Philips, and P. A. Williams, eds.), John Wiley, New York 1989 (Ellis Horwood), p. 391.

[3] A. J. Slaney, I. Nishiyama, P. Styring, and J. W. Goodby, J. Mater. Chem. 2, 805 (1992).

[4] P. Styring, J. D. Vuijk, I. Nishiyama, A. J. Slaney, and J. W. Goodby, J. Mater. Chem. 3, 399 (1993).

[5] I. Dierking, F. Gießelmann, P. Zugenmaier, W. Kuczynski, S. T. Lagerwall, and B. Stebler, Liq. Cryst. 13, 45 (1993).

[6] C. Loubser, P. L. Wessels, P. Styring, and J. W. Goodby, J. Mater. Chem. 4, 71 (1994).

[7] S. Hiller, L. A. Beresnev, S. A. Pikin, S. Wrobel, M. Pfeiffer, and W. Haase, 22. Freiburger Arbeitstagung Flüssigkristalle, 1993, Poster 33.

[8] M. Langner, D. Krüerke, K. Praefcke, and G. Heppke, 23. Freiburger Arbeitstagung Flüssigkristalle, 1994, oral presentation 24.

[9] G. Friedel, Ann. Phys. 18, 273 (1922).

[10] E. Sackmann, S. Meiboom, L. C. Snyder, A. E. Meixner, and R. E. Dietz, J. Amer. Chem. Soc. 9, 3567 (1968).

[11] H. Baessler, P. A. G. Malya, W. R. Nes, and M. M. Labes, Mol. Cryst. Liq. Cryst. 6, 329 (1970).

[12] H. Finkelmann and H. Stegemeyer, Z. Naturforsch. 28 a, 799 (1973).

[13] G. Heppke and F. Oestreicher, Z. Naturforsch. 32 a, 899 (1977).

[14] A. Göbl-Wunsch and G. Heppke, Z. Naturforsch. 34 a, 594 (1979). overall agreement for the twisting power between the calculated and experimental data is excellent.

\section{Conclusion}

A benzoic acid biphenyl ester with two chiral centers (M96) was introduced to prove the partial twisting power hypothesis by investigating the pitch of the supermolecular helical structure of five different opti$\mathrm{cal}$ isomers of the same constitution in the cholesteric phase. The R configuration at center " 1 " of M96 has not yet been synthesized, since the pure R-configured alcohole, necessary for the synthesis of this enantiomeric compound, is not available. However, we predict a twist inversion for ( $R, R)$-M96 from a rightto left-handed supermolecular cholesteric structure on temperature increase, for (R, S)-M96 a right-handed helix with the selective reflection wavelength in the visible range of the spectrum, for $\left(\mathrm{R}, \mathrm{RS}_{\mathrm{rac}}\right)$ - $\mathrm{M} 96$ a right-handed helical structure.

This work was supported by a grant from the Deutsche Forschungsgemeinschaft.

[15] G. Heppkc, H. Marschall, P. Nürnberg, F. Oestreicher and G. Scherowsky, Chem. Ber. 114, 2501 (1981).

[16] G. Heppke, F. Oestreicher and G. Scherowsky, Z. Naturforsch. 37a, 1176 (1982).

[17] G. Heppke, D. Lötzsch, and F. Oestreicher, Z. Naturforsch. 41 a, 1214 (1986).

[18] G. Heppke, D. Lötzsch, and F. Oestreicher, Z. Naturforsch. 42a, 279 (1987).

[19] M. Gunaratnc, PhD Thesis, Berlin 1988.

[20] B. Kirste and G. Scherowsky, Liq. Cryst. 6, 17 (1989).

[21] $\mathrm{H}$. Finkelmann and $\mathrm{H}$. Stegemeyer, Ber. Bunsenges. Phys. Chem. 78, 869 (1974).

[22] $\mathrm{H}$. Finkelmann and $\mathrm{H}$. Stegemeyer, Ber. Bunsenges. Phys. Chem. 82, 1302 (1978).

[23] M. Siekmeyer and P. Zugenmaier, Macromol. Chem., Rapid Commun. 8, 511 (1987).

[24] M. Siekmeyer and P. Zugenmaier, Cellulose, Structural and Functional Aspects (J. F. Kennedy, G. O. Phillips, and P. A. Williams, eds.), John Wiley, New York 1989 (Ellis Horwood), p. 349.

[25] P. Zugenmaier, Das Papier 28, 799 (1989).

[26] P. Zugenmaier, Cellulosics: Chemical, Biochemical and Material Aspects (J. F. Kennedy, G. O. Phillips, and P. A. Williams, eds.), John Wiley, New York 1993 (Ellis Horwood), p. 105.

[27] W. Maier and A. Saupe, Z. Naturforsch. 14a, 882 (1959).

[28] W. Maicr and A. Saupe, Z. Naturforsch. 15a, 287 (1960).

[29] W. J. A. Goossens, Mol. Cryst. Liq. Cryst. 12, 237 (1971).

[30] H. Stegemeyer, Ber. Bunsenges. Phys. Chem. 78, 860 (1974).

[31] B. W. van der Meer, G. Vertogen, A. J. Dekker, and J. G. J. Ypma, J. Chem. Phys. 65, 3935 (1976). 
[32] W. I A. Goossens, J. de Phys. 40, C3-158 (1979).

[33] M. A. Osipov, Nuovo Cim. 10, 1249 (1988).

[34] M. A. Osipov, Liquid Crystalline and Mesomorphic Polymers (V. P. Shibaev and L. Lam. eds.), SpringerVerlag, New York 1994, p. 1.

[35] H. G. Kuball. T. Müller, and H. G. Weyland, Mol. Cryst. Lig. Cryst. 215, 271 (1992).

[36] I. Dierking. F. Gießelmann, P. Zugenmaier, K. Mohr. H. Zaschke, and W. Kuczynski, Liq. Cryst.; in press.
[37] R. Cano, Bull. Soc. Fr. Miner. Cristallogr. 91, 20 (1968).

[38] F. Grandjean, C. R. Hebd. Seanc. Acad. Sci. Paris 172. 71 (1921).

[39] W. Kuczynski. S. T. Lagerwall, M. Matuszcyk, K. Skarp, B. Stebler, and J. Wahl, Mol. Cryst. Liq. Cryst. 146, 173 (1987).

[40] P. N. Keating. Mol. Cryst. Liq. Cryst. 8, 315 (1969). 